\title{
Study on the Issues that College Students Participating in the Management of Colleges and Universities
}

\author{
Chunfu Yang ${ }^{1 \mathrm{a}}$, Dongliang Yang ${ }^{2 \mathrm{~b}}$, Weihong $\mathrm{Min}^{3 \mathrm{c}^{*}}$ \\ ${ }^{1}$ College of Animal Science and Technology, Jilin Agricultural University, Changchun 130118, China \\ ${ }^{2}$ College of Information and Technology, Jilin Agricultural University, Changchun 130118, China \\ ${ }^{3}$ College of Food Science and Engineering, Jilin Agricultural University, Changchun 130118, China \\ ayangchunfu197242@163.com, b610557217@qq.com, 65817713@qq.com
}

*The corresponding author

Keywords: College Students; Participate in the management; Necessity; Related issues; Countermeasures

\begin{abstract}
It is the result of the deepen reform of higher education that college students participating in the management of colleges and universities, which is also an effective way to cultivate innovative talents and make their comprehensive development. This paper makes beneficial exploration from the necessity of college students participating in the management of colleges and universities, and the notable problems and countermeasures.
\end{abstract}

\section{Introduction}

It is necessary to cultivate socialist new talented college students by participating in the management of colleges and universities, and also the effective means to deepen the education reform and promote scientization and democratization process of education, as well as the inevitable trend of reform and innovation of college education and management mode, and the concrete practice to carry out the socialist core values, so it is a promising project for educating people.

The Necessity for College Students to Participate in the Management of Colleges and Universities

It is an important way for scientific management and democratic management in colleges and is the need to develop social democracy and the rule of law that college students to participate in the management of colleges and universities, which has important theoretical and practical basis.

From the Legal Level: The Education Law of the People's Republic of China Promulgated by the National People's Congress in 1995 Puts Forward that the Rights that Educators Should Have Include Participating in the Activities of School Teaching Plan, Schedule, Etc. In 2005, in Ordinary Colleges and Universities Student Management Regulation, the ministry of education definitely points out: "schools should build and perfect the organization forms for students to participate in the democratic management of schools, to insure and support students being involved in the democratic management of school as required by the law." That is to say, there are applied laws for abiding by, laws already enacted must be enforced to the letter, and law enforcement will benefit.

From the Practical Level: Higher Education Shows the Feature of Democratization that Makes the Desire and Possibility that College Students Participate in the Management of Colleges and Universities More Prominent, Particularly in the Management of Colleges and Universities. In order to maintain their own rights and interests, college students compete for democratic participation opportunity to make them expect the change from closed, centralized high education into diversification of participants. Therefore, more and more colleges and universities begin to encourage and support the students to participate in the management work. [1]

From the Level of Social Development: the United Nations Educational, Scientific and 
Cultural Organization Pointed out in the 21st Century Higher Education: the World Declaration of Outlook and Action that: in Current Fast-Changing World, Higher Education Obviously Need to Have New Student-Centered Perspective and Pattern... the Government, College and University Managers Should Take Students Need as the Focus, and Regard Them as the Main Participants in Higher Education Reform. It shall include that the students participate in the discussion, evaluation, reform of curriculum and teaching method of higher education, policy making and other management work of colleges and universities." It will become the trend and mainstream of worldwide higher education development stage that college students becoming the main body of colleges and universities management gradually. Democratization is the direction of deepening reform in current society, so it is in line with the characteristics of current era that college students to participate in the management of colleges and universities, it is imperative and urgent.

\section{Analysis of the Problems that College Students Participating in the Management of Colleges and Universities}

In recent years, quite a number of colleges and universities conforms to the requirements of The Times, and put it in the important agenda that college student participating in the management of colleges and universities, highlighting the students' subject status in the education teaching management. Students' participation is obviously improved, but from the current situation for college students in the management of colleges and universities. Students' participation requirement is far away from objective reality, mainly manifesting in the following aspects:

The Old Ideas. Mainly in two aspects: the leaders in some colleges and universities management have conventional concept and mode that putting students on the secondary, subordinate and passive position, which is important to say, minor to do, unnecessary under busy situation, existing in name only for students to participate in the management. Some students think that their knowledge and experience are insufficient, and it's impossible to change the management mode and method that have formed for long time, thus they lack of confidence, and even give up. There are still some students haven't realized themselves as the main body, and they think the management of colleges and universities has nothing to do with themselves and dispensable for them, failed to realize that participating in the management of colleges and universities is related with them, national event, which is political myopia.[2]

The Participation Rate Is Low. According to a survey, about $30 \%$ students have joined one or more management activities of schools, while most of the students are outside of school management. For the event which is closely linked with the students, such as curriculum management, student's participation rate is very low, and for those major management activities, and the involved students are even fewer. [3]

Insufficient Participation. For some tangible and sensitive issues that is close to the college students, such as dormitory problem, food problem. Students' participation is attached great importance, but for some invisible major issues, such as the establishment of school development planning, major initiatives in the teaching and education, students' participation is less. [4]However, the invisible issues play an important role in the development of school, achieving the goal of cultivating the students. In addition, prior to the decisions of school, symposium, seminar are often held or using questionnaire form to give students opportunity to participate in the management, but in the key stage of decision making, or major change in the process of execution, students are often excluded.

Single Participation Form. College students participate in the management of colleges and universities generally by the student union and youth league organization. In addition to the restriction of students' cadre work ability, the full effect of student organizations depends on the emphasis degree and the contents and carrier that the student to participate in the management.

Participation Mechanism Is not Sound. The contents that college students to participate in the management of colleges and universities mainly includes lead-in mechanism, incentive mechanism and guarantee mechanism. [5]From the present situation of colleges and universities, on the 
macroscopic education policy, neither the corresponding restriction mechanism, nor realistic operational incentive mechanism for the invasion or protection of students' rights, hindering or encouraging students to participate in school management behavior, and the lack of lead-in mechanism and guarantee mechanism is very important.

All of these have seriously restricted college students participating in management of colleges and universities.

\section{Countermeasures for College Students Participating In the Management of Colleges and Universities}

Truly Establishing the Subject Status of College Students, Enhancing the Participation Sense of College Students. Managers in colleges and universities must change ideas, and really realize the students, teachers and administrators are the three major groups. They are the strong driving force of educational reform and development, and also have the power to participate in the management and safeguard their own interests, which is the intrinsic demand of democratization and scientific process of colleges and universities. In these three major groups, teachers and administrators serves for students, and all work must take teacher as the leading factor, take the student as the main body, to cultivate innovative talents. [6]On the other hand, college students should also fully realize that they are the main body of teaching activities and management activities, and need to strengthen confidence, overcome the sadness and fear, and play an active role in management of colleges and universities. University and college administrators and teachers also should actively cultivate the students' participation sense and create more opportunities for them to participate in school management, providing more favorable conditions.

Improve the Relevant Policies and Regulations. Although the current laws give the power to college students for participating in the management of colleges and universities, but the participation contents, ways and methods are not clearly defined, which is bound to lead to leadership consciousness, weak legal awareness, and therefore it must be led into legal system that college students to participate in the management of colleges and universities. On the one hand, perfecting laws and regulations, to make it clear, specific and operational; On the other hand, acting in accordance with the law applied, eliminating various interventions. [7]

Establishing Mechanism and System Innovation. College students should participate in the management of colleges and universities conscientiously, to establish and perfect effective mechanism and sound system for guarantee. [8]Any important things that are closely related to the college students should listen to the opinions of students through various channels, at the same time some initiated management systems should be established to ensure participation of college students being implemented, to provide institutional and mechanism guarantee organization for organized, high quality material participation work.

Enhancing the Level of Quality and Participation. The first is to improve the ideological quality and professional level of university teachers and administrators, through workshops, academic report forms so that they have good quality and profound business, really becoming the organizer and guide for college students to participate in the management of colleges and universities; The second is to strengthen college students' participation awareness and participation ability. The lack of participation awareness and insufficient participation ability is an important factor restricting college students participating in the management of colleges and universities. This requires colleges and universities put students' participation in mind and at hand.[9] The participation quality of college students can be improved by relevant management training courses, seminar or providing opportunities, making them aware of their lower theory and insufficient capacity, cultivating their subject spirit, autonomous learning and the ability of self-management, focusing on cultivating their sense of responsibility, sense of mission, braveness to take on responsibilities, and ability to analyze and solve problems.

Creating Harmonious Atmosphere, Encouraging Students' Participation. To give full play to the role of the student union and communist youth league and others, participation expectation, active participation atmosphere should be built in students, and only in this way can students' 
enthusiasm to participate in the management can be increased, the number of people involved will be more and more, and the effect will be better and better. The promotional effect of cultivation of campus culture on college students participating in the management of colleges and universities should be attached great importance. Strong campus culture atmosphere is not only can improve the trust of teachers for college students participating in the management, but also can obtain the broad support of college students. Firstly, seminars for students participating in the management of colleges and universities should be held to build the academic atmosphere for students' participation; Secondly, propaganda and report forms can be used to make public opinion for students participating in the management of colleges and universities, to form good atmosphere; moreover, it can provide practice platform for students to participate in the management. Knowledge comes from practice, practice can exercise a person and bring up a person.[10]

Drawing Lessons from the Advanced Experience. Stone carved can be tuned into jade. At home and abroad, there are many mature approaches can be drawn lessons from, taking length of human, making up short ourselves, enriching and perfecting ourselves in a persistent way that college students will participate in the management of colleges and universities with more commendable situation.

\section{Conclusion}

Through the top design, and continuous work of administrators and teachers, students will actively participate in promoting the lawful process of college and university management, greatly stimulating the students' main body consciousness, democratic consciousness, participation consciousness, and improving students' ability of organization, coordination and participation, strengthening college students' sense of mission and sense of responsibility, then pushing the further development of reform, cultivating innovative talents for the new era needs. The promising education project to let college students participating in the management of colleges and universities will bloom more colorful flowers and bear rich fruit.

\section{References}

[1] G.L. Meng: Investigation and Analysis On Beijing College Students To Participate In Democratic Management Situation [I] Truth, 2010 (5) (In Chinese)

[2] L. Guo: The Construction of University Students' Management Idea System [j]. China's Adult Education, 2013 (21)(In Chinese)

[3] J. Wu:The Investigation Analysis and Countermeasures on College Students Participating in the Management of Colleges and Universities Situation [J]. Journal of Ideological and Political Education, 2014 (9)(In Chinese)

[4] D.W. Hu: Empirical Study on College Students Participating In the Management of Colleges and Universities under the Perspective Of Law [J]. Journal of Sichuan Institute of Technology (Social Science Edition), 2010 (6)(In Chinese)

[5] L.J. Wang: Consciousness Cultivation Selection of College Students Participating In the Management of Colleges and Universities [D]. Northwest University, 2013(In Chinese)

[6] M.F. Zhang: Revelation of American College Students Participating In the Management of Colleges and Universities [J]. China's Adult Education, 2010 (14)(In Chinese)

[7] Y.C. Jin: The thinking of College Students Participating In the Management of Colleges and Universities[J]. Journal of zhejiang university of technology(Social Science Edition),2011(1):19-24 (In Chinese)

[8] J.Hua,Y.Ding: College students to participate in the management of innovation research[J]. Education and vocational,2015(12):50-52(In Chinese) 
[9] Y. Long:A Study on University Students Participation in Democratic Management of their Universities in the New Age[J].Journal of Jilin Engineering Normal University,2016(7):33-35(In Chinese)

[10] Y.M. Ding:The studentswork in higher vocational colleges to practice the path of cultural management[J]. iamusi vocational college journal,2016(8):4-5,(In Chinese). 